
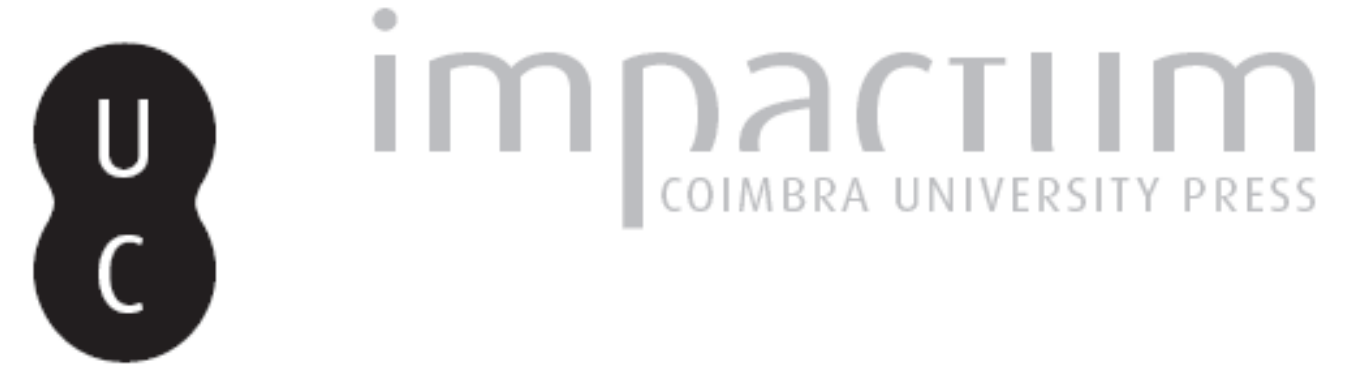

\title{
A gestão territorial dos riscos naturais e tecnológicos e o ordenamento do território: a perspectiva a partir do Plano Regional de Ordenamento do Território - Centro
}

Autor(es): $\quad$ Tavares, Alexandre Oliveira

Publicado por: CEDOUA

URL persistente:

URl:http://hdl.handle.net/10316.2/8834

DOI:

http://dx.doi.org/10.14195/2182-2387_22_2

Accessed : $\quad$ 26-Apr-2023 11:25:12

A navegação consulta e descarregamento dos títulos inseridos nas Bibliotecas Digitais UC Digitalis, UC Pombalina e UC Impactum, pressupõem a aceitação plena e sem reservas dos Termos e Condições de Uso destas Bibliotecas Digitais, disponíveis em https://digitalis.uc.pt/pt-pt/termos.

Conforme exposto nos referidos Termos e Condições de Uso, o descarregamento de títulos de acesso restrito requer uma licença válida de autorização devendo o utilizador aceder ao(s) documento(s) a partir de um endereço de IP da instituição detentora da supramencionada licença.

Ao utilizador é apenas permitido o descarregamento para uso pessoal, pelo que o emprego do(s) título(s) descarregado(s) para outro fim, designadamente comercial, carece de autorização do respetivo autor ou editor da obra.

Na medida em que todas as obras da UC Digitalis se encontram protegidas pelo Código do Direito de Autor e Direitos Conexos e demais legislação aplicável, toda a cópia, parcial ou total, deste documento, nos casos em que é legalmente admitida, deverá conter ou fazer-se acompanhar por este aviso.

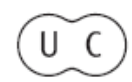





\section{A Gestão Territorial dos Riscos Naturais e Tecnológicos e o Ordenamento do Território. A perspectiva a partir do Plano Regional de Ordenamento do Território - Centro}

Resumo

\begin{abstract}
Num momento em que se apela para a necessidade de introdução da problemática dos riscos nos instrumentos de gestão territorial, torna-se particularmente pertinente determinar como é que estes têm vindo a considera-la no seu seio. 0 presente texto visa apresentar a forma como esta problemática foi tratada no âmbito do procedimento de elaboração do Plano Regional de Ordenamento do Território do Centro, o qual apresenta um modelo que faz salientar que a prevenção, redução e a mitigação dos riscos é a via a seguir na ocupação do território.
\end{abstract}

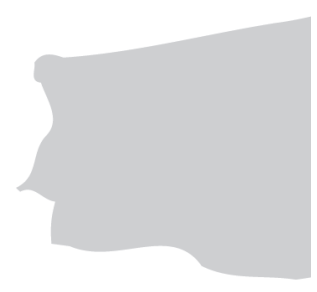

\section{Introdução}

Os riscos materializam processos ou acções, naturais ou tecnológicos, que adquirem relevância sócio-económica e têm expressão territorial, constituindo a análise e gestão dos riscos fora de acção e decisão integrantes das actividades em sociedade, embora com diferentes graus de visibilidade e explicitação $0^{1}$.

Os referenciais actuais demonstram condições globais de menor admissibilidade social, económica e jurídica às perdas e incertezas relacionadas com os processos e modelos, assumindo, por outro lado, importância crescente as respostas proactivas, preventivas e planeadas aos acontecimentos que possam afectar as expectativas, os objectivos estratégicos e tácticos das organizações². Nas chamadas sociedades de risco, em que aumenta a consciência individual e colectiva quanto aos potenciais perigos, e em que estes mesmos perigos podem assumir contornos difusos e terem efeitos prolongados no tempo, os cidadãos, técnicos, cientistas e agentes políticos organizam-se em torno desta problemática³. Os intervenientes projectam nos instrumentos e critérios de ordenamento e planeamento, bem como nas instituições da protecção civil, emergência e socorro, a capacidade de gestão dos riscos, ao nível local, regional, nacional e global4.

${ }^{1}$ CANTOS, J. O.; AYALA-CARCEDO, F. J. (2002) - Riesgos naturales. Conceptos fundamentales y clasificación. In CANTOS, Jorge Olcina e AYALA CARCEDO, Francisco Javier (Ed.) - Riesgos naturales, Ariel Ciencia, Barcelona; pp. 41-74. ${ }^{2}$ JASANOFF, S. (2005) - Designs on nature. Science and democracy in Europe and United States. Princeton: Princeton University Press, 392p.

${ }^{3}$ KASPERSON J., KASPERSON R.; DOW K. (2001). Global environmental risk and society in Global environmental risk. Kasperson JX and Kasperson R (eds), United Nation University Press, Earthscan, London, pp. 247-271

4 ECDGE (2008) - Assessing the potential for a comprehensive community strategy for te prevention of natural and manmade disasters. Final Report. European Commission DG Environment.COWI, Kongens Lyngby, 11op. 
Com as transformações globais, as dinâmicas populacionais de urbanização e litoralização, a não reversibilidade de muitos dos processos naturais, adquirem importância a expressão espacial dos riscos e a qualificação da probabilidade de ocorrência de eventos extraordinários. A preocupação dos cidadãos, das comunidades, das instituições, ou dos estados, relativamente aos valores ambientais e aos critérios de segurança e fiabilidade dos processos, estruturas e equipamentos, determina a incorporação de princípios éticos na gestão dos perigos.

A Estratégia Nacional para o Desenvolvimento Sustentável - ENDS55, salienta no diagnóstico um quadro importante de riscos naturais e ambientais em Portugal, a par das preocupações dos incêndios florestais e da gestão dos recursos hídricos, num referencial de dinâmica diferenciada no território e processos de concentração populacional e de urbanização acentuados. No âmbito do objectivo - Melhor Ambiente a Valorização do Património - é salientada a necessidade de promoção de uma política de gestão dos riscos naturais e tecnológicos, envolvendo as populações expostas aos riscos, visando mitigar os respectivos efeitos. A ENDS propõe um conjunto de vectores fundamentais ${ }^{6}$ para a concretização dos objectivos os quais explicitam as estratégias de territorialização e gestão dos riscos naturais e tecnológicos, assim como considera prioritária a definição dos diferentes tipos de riscos naturais, ambientais e tecnológicos, em sede dos Planos Regionais de Ordenamento do Território, dos Planos Municipais de Ordenamento do Território e dos Planos Especiais de Ordenamento do Território e, consoante os objectivos e critérios de cada tipo de plano, as áreas de perigosidade e os usos compatíveis respectivos, bem como as medidas de prevenção e mitigação dos riscos identificados, para o período 2007-2013.

O Programa Nacional da Política de Ordenamento do Território - PNPOT, como cúpula do sistema de gestão territorial, e elemento fundamental de referência e orientação para as decisões de gestão territorial, estabelece como objectivos:

- a criação de um espaço sustentável e bem ordenado;

- a preservação de um quadro natural e paisagístico, e em particular dos recursos hídricos, da orla costeira, da floresta e dos espaços com potencial agrícola;

- a criação, nomeadamente, de um modelo territorial coerente comportando um sistema de prevenção e gestão dos riscos;

- a gestão sustentável dos recursos naturais e dos espaços agro-florestais, assim como o reforço da qualidade e eficiência da gestão territorial, promovendo a participação informada, activa e responsável dos cidadãos e das instituições.

O PNPOT aponta como objectivos estratégicos específicos, nomeadamente, avaliar e prevenir os factores e as situações de risco, bem como desenvolver dispositivos e medidas de minimização dos respectivos efeitos, a par da definição e execução de uma política de ordenamento, planeamento e gestão integrada da zona costeira, nas vertentes terrestre e marítima, ou ainda a articulação dos planos de ordenamento florestal, planos de gestão florestal e planos de defesa da floresta contra incêndios, com as políticas de desenvolvimento rural. Um dos problemas de ordenamento para o desenvolvimento do território apontado é a insuficiente salvaguarda e valorização dos recursos naturais e a ineficiente gestão dos

\footnotetext{
5 Resolução do Conselho de Ministros nํㅜ109/2007, de 20 de Agosto, DR 159 Série I

${ }^{6}$ Promover e Implementar a Estratégia de Gestão Integrada da Zona Costeira e Promover o Ordenamento das Zonas Envolventes de Estuários e Albufeiras; Promover a Segurança Marítima e a Prevenção dos Acidentes nos Oceanos; Gestão Sustentável dos Recursos Florestais e sua Protecção Adequada; Melhoria da Capacidade de Monitorização e Prevenção dos Riscos Sísmicos e Gestão dos seus Efeitos, Designadamente sobre o Edificado; Prevenção de Impactos de Outros Riscos Naturais e Tecnológicos, designadamente Cheias, Secas e Acidentes de Poluição.

7 Decreto Lei no 58/2007, de 4 de Setembro, DR 170 Série I
} 
riscos naturais, sendo apontado um conjunto de medidas prioritárias visando a sua resolução, nomeadamente:

- a gestão e ordenamento florestal e defesa contra incêndios;

- a gestão e ordenamento da orla costeira;

- a gestão e protecção marítima

- a avaliação, prevenção e minimização de riscos naturais, ambientais e tecnológicos;

- a intervenção de protecção e socorro em ocorrências de incêndios florestais ou de matérias perigosas e em catástrofes e acidentes graves;

- a definição de um sistema integrado de circuitos para o transporte, armazenagem, eliminação e valorização de resíduos industriais;

- a gestão e protecção das reservas estratégicas da água;

- a adopção de comportamentos defensivos e seguros;

- o desenvolvimento de acções de sensibilização, educação e mobilização dos cidadãos para ordenamento territorial.

Tendo como referência estes dois documentos estratégicos e ainda as orientações gerais propostas para os Planos Regionais de Ordenamento do Território ${ }^{8}$, em que se salienta, nomeadamente:

- a definição de directrizes para o uso, ocupação e transformação do território, num quadro de opções estratégicas a nível regional;

- a promoção, no plano regional, da integração de políticas sectoriais e ambientais no ordenamento do território e a coordenação das intervenções;

- a orientação dos Planos intermunicipais e municipais de ordenamento do território;

- o estabelecimento de directivas relativas aos regimes territoriais especiais (reserva agrícola, reserva ecológica e domínio hídrico);

- a identificação dos espaços sub-regionais com vista à operacionalização e à definição

de estratégias específicas de intervenção;

- a definição de normas específicas, entre outras, visando a segurança e protecção civil, bem como regimes territoriais especiais;

que se construiu a matriz inicial de diagnóstico e visão dos Riscos Naturais e Tecnológicos para a Região Centro de Portugal.

A sistemática dos perigos elencados no PNPOT, assim como as características biogeofísicas do território ou as dinâmicas e fluxos sócio-económicos, fundamentaram a análise reflexiva dos processos e acções de risco na Região Centro, bem como a respectiva incidência territorial. A análise da vulnerabilidade ambiental ou humana, relacionada com os elementos expostos, a contextualização das práticas e vivências culturais, bem como a disponibilidade e efectividade das medidas estruturais e não estruturais de mitigação do risco, a diferentes escalas, constituíram referenciais de análise e de cenarização estratégica no âmbito do Plano Regional de Ordenamento do Território - Centro (PROT - Centro).

\section{0 quadro de referência do PROT - Centro}

A Região Centro é representada por um território de $23666 \mathrm{~km}^{2}$, com 1783596 habitantes 9 (INE, 2001), a que correspondem 78 municípios, repartidos por 10 NUT III. Trata-se de um espaço caracterizado por fortes contrastes morfológicos, pela diversidade litológica inscrita num quadro estrutural complexo, por variações climáticas significativas a nível espacial, por

\footnotetext{
${ }^{8}$ MAOTDR-GSEOTC (2005). PROT 2006. Orientações gerais para a elaboração dos Planos Regionais de Ordenamento do Território, Ministério do Ambiente, Ordenamento do Território e Desenvolvimento Rural, Gabinete do Secretário de Estado do Ordenamento do Território e das Cidades, p. 24

9 INE (2001). Censos 2001. Resultados da Região Centro. Instituto Nacional de Estatística, Lisboa, p. 175.
} 
diferentes potencialidades hidrogeológicas, com regimes hidrológicos muito marcados pela sazonalidade, por diversas apetências agrícolas e florestais, por dinâmicas demográficas e sócio-económicas diferenciadas, pela heterogeneidade da concentração urbana e produtiva, as quais condicionam o quadro ambiental e de segurança existente.

Uma análise histórica do registo de desastres e acidentes graves na Região, faz salientar um número alargado de processos ou acções que têm determinado perdas e danos avulta$\operatorname{dos}^{10}$. Uma análise mais detalhada faz ainda ressaltar que muitos dos processos têm magnitudes e severidades territorialmente muito distinta, expressão espacial desde escalas locais a supra-regionais, e incidência temporal variando desde episódica a irreversível.

A Resolução do Conselho de Ministros n. ${ }^{0} 31 / 2006^{11}$ atribuiu à Comissão de Coordenação e Desenvolvimento Regional do Centro a elaboração do Plano Regional de Ordenamento do Território - Centro (PROT - Centro), tendo estabelecido as orientações para os objectivos estratégicos e para o Modelo Territorial, delimitado o âmbito territorial e fixado a composição da Comissão Mista de Acompanhamento do Plano. Ao PROT - Centro cabe assim, definir as estratégias regionais de desenvolvimento territorial, integrando as opções estabelecidas a nível nacional e considerando as estratégias municipais de desenvolvimento local, constituindo o quadro de referência para a elaboração dos planos especiais, intermunicipais e municipais de ordenamento.

No âmbito dos trabalhos de construção da proposta do PROT Centro, e iteração com a Comissão Mista de Acompanhamento, foi constituído um Grupo de Trabalho formado por diferentes equipas que representavam os seguintes sistemas estruturantes para o Diagnóstico e Visão regional: sistema produtivo (prospectiva económica e inovação, desenvolvimento rural e actividades agro-florestais, turismo e património cultural, energia), sistema urbano, sistema de acessibilidades e transportes, sistema de protecção e valorização ambiental e sistema de riscos naturais e tecnológicos.

Os objectivos base de trabalho consistiam na elaboração de propostas para o Plano que incluíam: (i) a criação de uma visão regional; (ii) a definição de um conjunto de opções estratégicas de base territorial; (iii) o desenho dos sistemas estruturantes regionais; (iv) a definição de unidades territoriais de gestão; (v) a proposta de um quadro normativo e orientador; (vi) a construção de um sistema de monitorização e avaliação do plano; (vii) a proposta de um programa de execução; (viii) a avaliação da incidência ambiental do Plano.

A construção do sistema estruturante para os Riscos Naturais e Tecnológicos, no âmbito do PROT - Centro, foi concretizada por uma equipa oriunda da Universidade de Coimbra e envolvendo docentes e investigadores das Faculdades de Ciências e Tecnologia, de Letras e de Economia. A equipa pluridisciplinar incluía engenheiros geólogos, engenheiros mecânicos, engenheiros do ambiente, geólogos, geógrafos e sociólogos, para além de técnicos de Sistemas de Informação Geográfica, tendo as actividades regulares decorrido entre 2006 e 2009.

\section{0 Diagnóstico e Visão territorial dos Riscos Naturais e Tecnológicos}

No âmbito da participação nas actividades do PROT-Centro, a equipa do sistema estruturante dos Riscos Naturais e Tecnológicos estabeleceu um cronograma de análise para a Região que incluiu as seguintes tarefas:

- Identificação e classificação tipológica, à escala regional, dos diferentes processos ou eventos perigosos;

- Avaliação, à escala regional, da magnitude e severidade dos vários perigos;

${ }^{10}$ TAVARES, A.; CUNHA, L. (2007). Riscos naturais e ordenamento do território. Espaços-risco e interfaces territoriais na Região Centro. Actas do VI Congresso da Geografia Portuguesa, Lisboa, 12 p.

${ }^{11}$ Resolução do Conselho de Ministros n.ํㅜ 31/2006, de 23 de Março, DR 59 Série I-B 
- Definição e expressão cartográfica, à escala regional, da susceptibilidade aos vários perigos;

- Identificação dos elementos expostos e aferição de uma escala de vulnerabilidade social para os vários perigos;

- Construção de índices de vulnerabilidade social à escala municipal;

- Definição de interfaces e Espaços-Risco determinantes para o modelo territorial.

Os primeiros pontos de análise basearam-se no levantamento de um conjunto alargado de trabalhos científicos, relatórios técnicos e de outras fontes. Fizeram-se consulta e inquirições a entidades ou instituições relacionadas com a gestão dos perigos/riscos, tendo-se organizado uma sessão de trabalho com os representantes dos CDOS (Comandos Distritais de Operações de Socorro) de Aveiro, Castelo Branco, Coimbra, Leiria, Guarda e Viseu, a quem foram propostas um conjunto de matrizes de avaliação do risco bem como do worst-case-scenario. Incorporou-se na análise um conjunto alargado de cartografia temática e de representações síntese ao nível de planos de ordenamento, gerais ou sectoriais, a diferentes escalas.

Foram considerados na análise, e com expressão territorial, os perigos que transparecem na Tabela 1.

\begin{tabular}{|c|c|c|}
\hline \multicolumn{3}{|c|}{ Perigos } \\
\hline Natureza & & Tipologia \\
\hline \multirow{4}{*}{$\begin{array}{l}\text { Geodinâmica } \\
\text { (interna e externa) }\end{array}$} & Sismicidade & \\
\hline & Radioactividade natura & \\
\hline & Movimentos de massa & entes \\
\hline & Erosão costeira & Sistemas praia/duna \\
\hline \multirow{7}{*}{ Climática } & & Arribas coesivas \\
\hline & Cheias/Inundações & Cheias progressivas \\
\hline & & Cheias rápidas \\
\hline & Episódios de seca & \\
\hline & Ondas de calor & \\
\hline & Ondas (vagas) de frio & \\
\hline & Incêndios florestais & $\begin{array}{l}\text { Contexto florestal, em espaços naturais e } \\
\text { protegidos, e em espaços de interface } \\
\text { rural/urbano }\end{array}$ \\
\hline \multirow{5}{*}{ Tecnológica } & Transporte marítimo & $\begin{array}{l}\text { Associado ao derrame de hidrocarbonetos, } \\
\text { na orla costeira e oceânica, de acordo com } \\
\text { as características topo-hidrográficas e } \\
\text { geomorfológicas }\end{array}$ \\
\hline & Cheias e inundações & $\begin{array}{l}\text { Decorrentes da onda de rotura de barragens } \\
\text { e mini-hídricas }\end{array}$ \\
\hline & $\begin{array}{l}\text { Actividade industrial e } \\
\text { comercial }\end{array}$ & $\begin{array}{l}\text { Armazenamento, manuseamento } \\
\text { transformação de matérias perigosas; }\end{array}$ \\
\hline & \multicolumn{2}{|c|}{ Transporte, circulação e distribuição de mercadorias perigosas } \\
\hline & $\begin{array}{l}\text { Condições ambientais } \\
\text { degradadas }\end{array}$ & das a áreas mineiras abandonadas ou \\
\hline
\end{tabular}

Tabela 1 - Perigos analisados no âmbito do PROT - Centro

A tarefa de identificação dos perigos constituiu uma fase criativa, envolvendo a identificação de múltiplos cenários e disfunções dos sistemas, e privilegiou visões multidisciplinares, valorizando interacções e efeitos conjugados. 
A fase analítica seguinte incluiu a gestão, cruzamento e análise dos dados de input, os quais permitiram espacializar, para cada processo ou acção perigosa, as áreas de susceptibilidade, com previsível ou não, anexação de escalas de severidade ou probabilidade.

$\mathrm{Na}$ FIGURA 1 aparece representado o quadro conceptual de avaliação, comportando os processos de análise e as interacções propostas para avaliação dos riscos para a PROT - Centro, procurando referenciar os critérios de territoralização, a existência ou não de adaptações estruturais ou não estruturais, e os efeitos reprodutivos para acções estratégicas, ao nível das políticas de ordenamento ou ao nível da protecção civil, no que concerne à prevenção e à operacionalização da emergência e socorro.

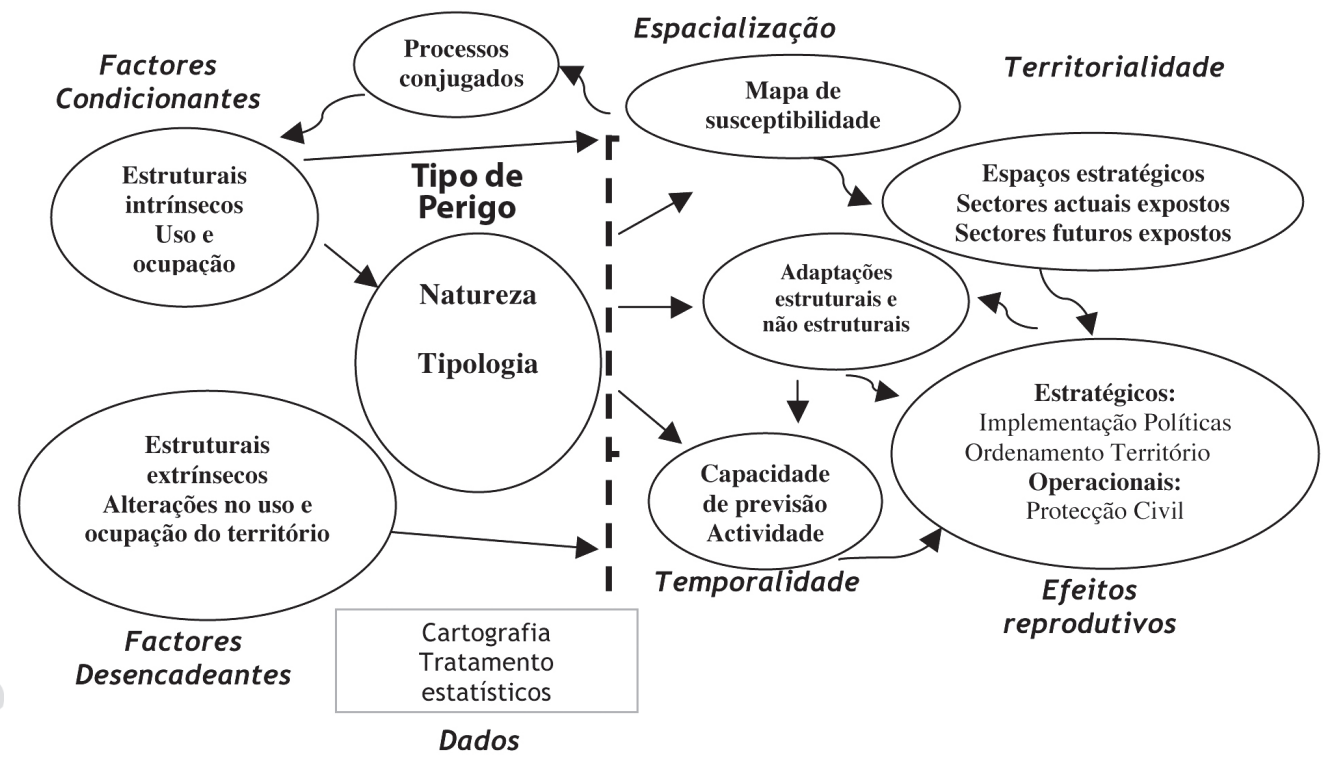

Figura 1 - Quadro conceptual de avaliação dos perigos e da reprodutibilidade da análise

A análise da vulnerabilidade social encetada, inédita ao nível dos diferentes PROT, está associada ao grau de exposição e à capacidade de resistência e de resiliência social aos perigos, tendo sido utilizados factores ${ }^{12}$ como: falta de acesso a recursos; falta de acesso à representação política; o capital social, que inclui as redes sociais; as crenças e costumes (cultura); a tipologia e idade do edificado para habitação; a qualidade das infra-estruturas; as estruturas e serviços de emergência e socorro; o peso de grupos críticos $^{13}$.

A caracterização e cartografia quer da susceptibilidade como da vulnerabilidade foi baseada em critérios de homogeneidade e dispersão de variáveis, de forma a obter representações espaciais em índices com graus crescentes - tendencialmente cinco, com ulterior legibilidade à escala municipal, intermunicipal ou das NUT III.

Na Figura 2 aparece representada a distribuição espacial compósita dos graus elevados e muito elevados de susceptibilidade para a Região Centro.

12 CUTTER, S.; BORUFF, B. \& SHIRLEY, W. (2003). Social Vulnerability to Environmental Hazards. Social Science Quarterly 84(1), pp. 242-261.

${ }^{13}$ MENDES, J. M. (2009). Social vulnerability indexes as planning tools: beyond the preparedness paradigm. Journal of Risk Research, Volume 12 (1), pp. 43 - 58 


\section{$\operatorname{RerCEDöUA~}$}

$>$ Doutrina

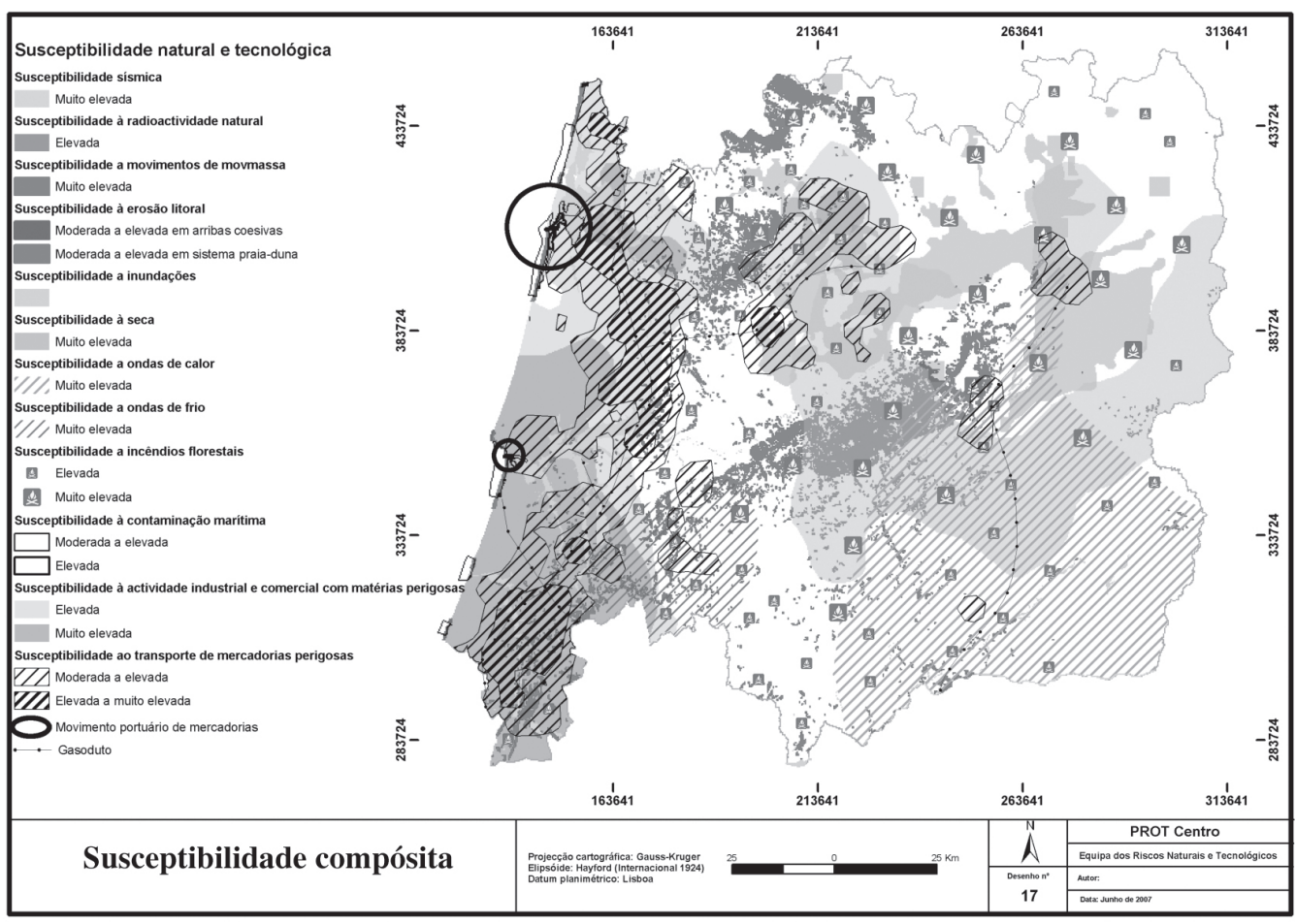

Figura 2 - Cartografia síntese dos graus elevados de susceptibilidade na Região Centro

Do cartograma ressalta, nomeadamente:

- a susceptibilidade específica patente na orla costeira, quer associada a processos naturais, tecnológicos e antrópicos;

- a associação de valores elevados de susceptibilidade natural e tecnológica no Centro Litoral e na transição para o Maciço Hespérico;

- a expressão da susceptibilidade muito elevada relacionada com a climatologia e com episódios meteorológicos extremos no Interior, nomeadamente a sul do Maciço Central; - a expressão territorial alargada da susceptibilidade relacionada com os incêndios florestais, em solo rural e urbano, e afectando espaços com ocupação antrópica e de interface urbana, espaços florestais, espaços agrícolas, espaços naturais e protegidos;

- a expressão sumativa da perigosidade natural e tecnológica, embora descontínua, no espaço de Dão-Lafões e da Serra da Estrela.

De acordo com a espacialização da susceptibilidade e da vulnerabilidade, da leitura das interacções sectoriais e a reprodutibilidade nas políticas de prevenção, redução ou mitigação dos riscos, bem como das políticas de protecção e socorro na Região Centro, foram identificados um conjunto de pressupostos que ulteriormente viriam a condicionar o Modelo Territorial, assim como a proposição das Orientações e Normas.

O diagnóstico encetado permitiu ao sistema estruturante dos Riscos Naturais e Tecnológicos estabelecer uma visão para a Região, assinalando algumas inconformidades e disrupções nas políticas públicas, nomeadamente no quadro ambiental e do ordenamento do território, assim como algumas estratégias a potenciar ou a explicitar. Apontam-se seguidamente alguns dos referenciais resultantes do diagnóstico e visão: 
- A interpretação dos riscos naturais e tecnológicos na Região Centro, numa lógica de prevenção e mitigação, permite incrementar a capacidade de suporte e a resiliência das populações e territórios;

- O diagnóstico e representação dos riscos naturais e tecnológicos é feita preferencialmente às escalas municipais e intermunicipais, enquanto que a operacionalização do socorro e emergência privilegia escalas supra-municipais a nacionais;

- Os riscos naturais e tecnológicos são determinantes ao nível regional nas opções de qualificação ambiental, na definição dos fluxos urbanos e no suporte da inovação, na definição e na hierarquização da rede de acessibilidades;

- Os modelos de consolidação e expansão urbana reflectem historicamente condicionantes determinadas pelos riscos naturais;

- As fragilidades e potencialidades da orla costeira, função dos valores ambientais e da dinâmica de transformação, impõem uma monitorização e gestão integrada dos riscos naturais e tecnológicos;

- As condições de ondas de calor estão associadas a outros riscos sumativos como sejam as secas e os incêndios, nomeadamente os florestais;

- A gestão e qualificação de áreas protegidas e de conservação da natureza estão dependentes de medidas de prevenção e mitigação de riscos naturais e tecnológicos;

- A materialização dos riscos naturais e tecnológicos impõe constrangimentos e limitações nos fluxos e dinâmicas nacionais e transnacionais que cruzam a Região Centro ao nível, por exemplo, da circulação rodoviária e ferroviária, na exploração e distribuição energética, na captação e distribuição e abastecimento de recursos hídricos;

- A territoralização e cenarização dos riscos tecnológicos devem suportar as opções de desenvolvimento e espacialização dos sectores industriais e infra-estruturação energética e de acessibilidades;

- Os modelos de desenvolvimento rural e de protecção da floresta e dos espaços naturais condicionam os sectores produtivos, como o turístico, os quais estão dependentes da magnitude e severidade dos índices de perigosidade natural;

- A implementação de um quadro regional de qualificação ambiental e de segurança das pessoas e bens está relacionada com a efectivação de estratégias de remediação e monitorização em áreas mineiras abandonadas ou degradadas;

- A diversificação e adequação das estratégias de uso e transformação do território promovem, por si só, a mitigação dos riscos e contribuem para a coesão territorial da Região; - O policentrismo da Região Centro apresenta-se como potenciador e como uma oportunidade para estruturar o território de forma a diminuir ou mitigar a vulnerabilidade social aos riscos naturais e tecnológicos;

- A tendência relativa de macrocefalia dos grandes centros urbanos deve ser contrariada por políticas de ordenamento do território e por lógicas institucionais e organizacionais que, a nível da prevenção e mitigação dos riscos e da emergência e socorro, operem explicitamente no sentido de proceder a uma efectiva desconcentração espacial (por exemplo, na localização geográfica e nas suas redes articuladas de actuação);

- A percepção e sensibilização aos riscos, bem como a adopção de comportamentos de segurança, possibilitam o desenvolvimento de competências no âmbito da educação, nomeadamente para o ambiente, sustentabilidade e cidadania.

O referencial estabelecido a partir do diagnóstico e visão, permitiu a concretização dos seguintes vectores territoriais estratégicos para a Região Centro:

- a expressão espacializada da susceptibilidade natural e tecnológica, bem como da vulnerabilidade social;

- a articulação com outros instrumentos de ordenamento pré-existentes; 


\section{$\operatorname{RerCEDöUA~}$

- a articulação com os outros quadros sectoriais do PROT-Centro;

- a articulação com outros instrumentos e políticas públicas estruturantes para a Região;

- a construção de um Modelo Territorial para implementação das políticas públicas e desenvolvimento das estratégias de prevenção, redução e mitigação do risco;

- a contribuição para um Modelo Territorial global para a Região Centro.

\section{0 contributo dos Riscos para o Modelo Territorial da Região}

O Programa Nacional da Política de Ordenamento do Território ${ }^{14}$ realça a importância da criação de um Modelo Territorial coerente comportando um sistema de prevenção e gestão dos riscos, assim como considera nos objectivos estratégicos de desenvolvimento regional, a avaliação e prevenção de factores e de situações de risco com vista ao desenvolvimento de medidas de minimização dos respectivos efeitos. De acordo com as orientações gerais propostas para os Planos Regionais, estabeleceu-se, entre outras, a identificação dos espaços sub-regionais com vista à operacionalização e à definição de estratégias específicas de intervenção ${ }^{15}$.

O diagnóstico e visão estabelecida previamente pelo sistema estruturante dos Riscos Naturais e Tecnológicos para o PROT-Centro, fez ressaltar um conjunto de processos que, pela probabilidade de ocorrência, magnitude e severidade associadas, determinam recorrentes perdas e danos avultados, quer materiais, quer humanos, e para os quais é possível uma territorialização.

Este conjunto de processos, impactos e incidência espacial, são determinantes na construção do Modelo Territorial Regional, dado que condicionam quer:

- a definição da visão estratégica regional, e para as diferentes unidades estruturantes;

- a interacção com os vários sectores estruturantes da Região;

- a construção e efectivação dos vários Quadros de Referência, actuais e futuros.

Neste contexto foram realizadas para a Região Centro, as representações territoriais, compósitas ou parcelares, dos processos ou acções sempre que apresentam graus de susceptibilidade elevada a muito elevada, dada a relevância para as políticas e estratégias de ordenamento do território, bem como para as condições operacionais de protecção civil.

Foi igualmente considerada fundamental na explicitação do Modelo Territorial a transposição da expressão da vulnerabilidade social municipal versus a densidade populacional municipal, permitindo assim espacializar os contrastes da população exposta aos perigos naturais e tecnológicos. A cartografia de vulnerabilidade criada permitiu aquilatar das diferenças municipais entre a capacidade instalada e a resiliência das populações e perspectivar acções visando a coesão territorial e social.

A Equipa do sistema estruturante dos Riscos pode, assim, contribuir para um modelo regional global integrador, que simultaneamente identificasse objectivos e estratégias territoriais diferenciadas que incluíssem nomeadamente:

- directrizes para o uso, ocupação e transformação do território;

- estratégias de prevenção e redução da perigosidade;

- integração de políticas sectoriais e ambientais no ordenamento do território e a coordenação das intervenções;

- orientações para os planos intermunicipais e municipais de ordenamento do território;

${ }^{14}$ PNPOT (2007). Programa Nacional da Política de Ordenamento do Território. Relatório anexo à Lei nº 58/2007, de 4 de Setembro, DR 170 Série I

${ }^{15}$ MAOTDR-GSEOTC (2005). PROT 2006. Orientações gerais para a elaboração dos Planos Regionais de Ordenamento do Território, Ministério do Ambiente, Ordenamento do Território e Desenvolvimento Rural, Gabinete do Secretário de Estado do Ordenamento do Território e das Cidades, p. 24 
- directivas relativas aos regimes especiais de ordenamento do território;

- operacionalização e definição de estratégias específicas para o socorro e emergência;

- redução da vulnerabilidade social;

- criação de normas específicas de segurança e protecção civil, bem como de comportamentos defensivos e seguros;

- construção de modelos de participação e envolvimento das entidades públicas e das organizações;

- implementação de acções de sensibilização, educação e mobilização dos cidadãos.

A tarefa seguinte comportou a definição das associações espaciais da susceptibilidade e da vulnerabilidade social, o que permitiu traçar uma cartografia de diferentes EspaçosRis $^{16,17}$ e salientar interfaces territoriais, particularmente sensíveis, determinantes na optimização da gestão dos riscos, mas igualmente na interacção com outros sistemas estruturantes em análise no PROT-Centro, como o quadro de referência ambiental, o modelo urbano e a perspectiva económica e de inovação.

Na Figura 3 aparecem representados os Espaços-Risco definidos para a Região Centro, os quais apresentam relativa homogeneidade tipológica e de grau de incidência dos factores da equação do risco. Os espaços risco encontrados foram os seguintes:

1 - Espaço Litoral, em que a susceptibilidade relacionada com os processos de geodinâmica externa apresenta graus elevados, nomeadamente os relacionados com a erosão costeira, as inundações e, com menor incidência, a sismicidade. Este espaço é ainda diferenciado pelos, genéricos, baixos graus de susceptibilidade relacionado com os processos climáticos ou condições meteorológicas extremas. Estão patentes elevados níveis de susceptibilidade relacionada com as actividades industriais e comerciais com matérias perigosas, as decorrentes do transporte e manuseamento de mercadorias perigosas. A vulnerabilidade social reflecte o carácter policêntrico, com claros contrastes municipais, correspondendo na relação com a densidade da população exposta aos valores mais elevados da região.

2 - Espaço de transição Litoral/Interior, onde transparece a elevada susceptibilidade relacionada com os processos de geodinâmica externa, nomeadamente os movimentos de massa e as cheias/inundações, e com menor incidência com a sismicidade. Constitui ainda um espaço em que as condições meteorológicas extremas reflectem índices elevados de susceptibilidade relacionados com as ondas de calor e frio, e com os incêndios florestais. Este espaço é ainda identificado pela expressão elevada a muito elevada da susceptibilidade relacionada com o transporte mercadorias perigosas, distribuição energética, bem como da decorrente das actividades industriais e comerciais com matérias perigosas. Reflecte ainda pontualmente a perigosidade relacionada com áreas mineiras abandonadas ou degradadas. A vulnerabilidade social vs. a densidade populacional exposta apresenta índices elevados, nomeadamente a norte, e reflecte o carácter policêntrico da estruturação e organização municipal.

3 - Espaço do Alto Vouga e do Médio e Alto Mondego, representado por uma susceptibilidade elevada relacionada com a geodinâmica, onde sobressai a radioactividade natural e os movimentos de massa em vertentes, bem como com as condições meteorológicas que determinam os incêndios florestas ou as ondas de calor. Apresenta um risco crescente a actividades industriais e comerciais com matérias perigosas, bem como as relacionadas com o transporte viário de mercadorias perigosas. Apresenta um número elevado de áreas mineiras abandonadas ou degradadas, em processos diferenciados de remediação e qualificação ambiental. A vulnerabilidade social expressa a influência urbana de Viseu/Tondela nos espaços de hinterland, com índices de moderados quando projectada a densidade populacional.

${ }^{16}$ CANTOS, J. \& AYALA-CARCEDO, F. (2002). Riesgos Naturales. Conceptos fundamentales y clasificación. Riesgos Naturales. Ed. Ariel, Ciência, Barcelona, pp. 41-73.

${ }^{17}$ HEWWITT, K. (1999). Regions of risk: hazard, vulnerability and disasters. Ed. Pearson-Longman, London, p. 389 
4 - Espaço do Maciço Central e Beira Serra sul, no contexto regional este espaço apresenta uma elevada incidência dos processos climáticos e meteorológicos extremos, que determinam uma elevada susceptibilidade à seca, a ondas de calor e de frio, e a incêndios florestais. Os processos associados à geodinâmica, embora com menor incidência territorial, determinam elevados graus de susceptibilidade relacionados com os movimentos de massa, cheias e inundações. Apresenta uma susceptibilidade pontual a actividades industriais e comerciais com matérias perigosas, assistindo-se a um incremento do risco associado ao transporte viário de mercadorias perigosas. Regista valores de perigosidade relacionados com áreas mineiras abandonadas ou degradadas, em processos diferenciados de remediação e qualificação ambiental. A vulnerabilidade social, com contrastes municipais claros, tem uma expressão limitada pela baixa densidade da população exposta.

5 - Espaço Raiano, onde a maior susceptibilidade aos processos naturais aparece associada às ondas de calor e a períodos de seca. De salientar ainda a susceptibilidade relacionada com a sismicidade e as inundações. Assiste-se a um incremento do risco relacionado com o transporte de mercadorias perigosas. Regista-se o perigo pontual associado a explorações mineiras abandonadas ou degradas. A vulnerabilidade social apresenta valores contrastados, reflectido o tecido produtivo bem como a infraestruturação e organização municipal, mas que traduz uma exposição muito baixa dados os reduzidos valores de densidade populacional.

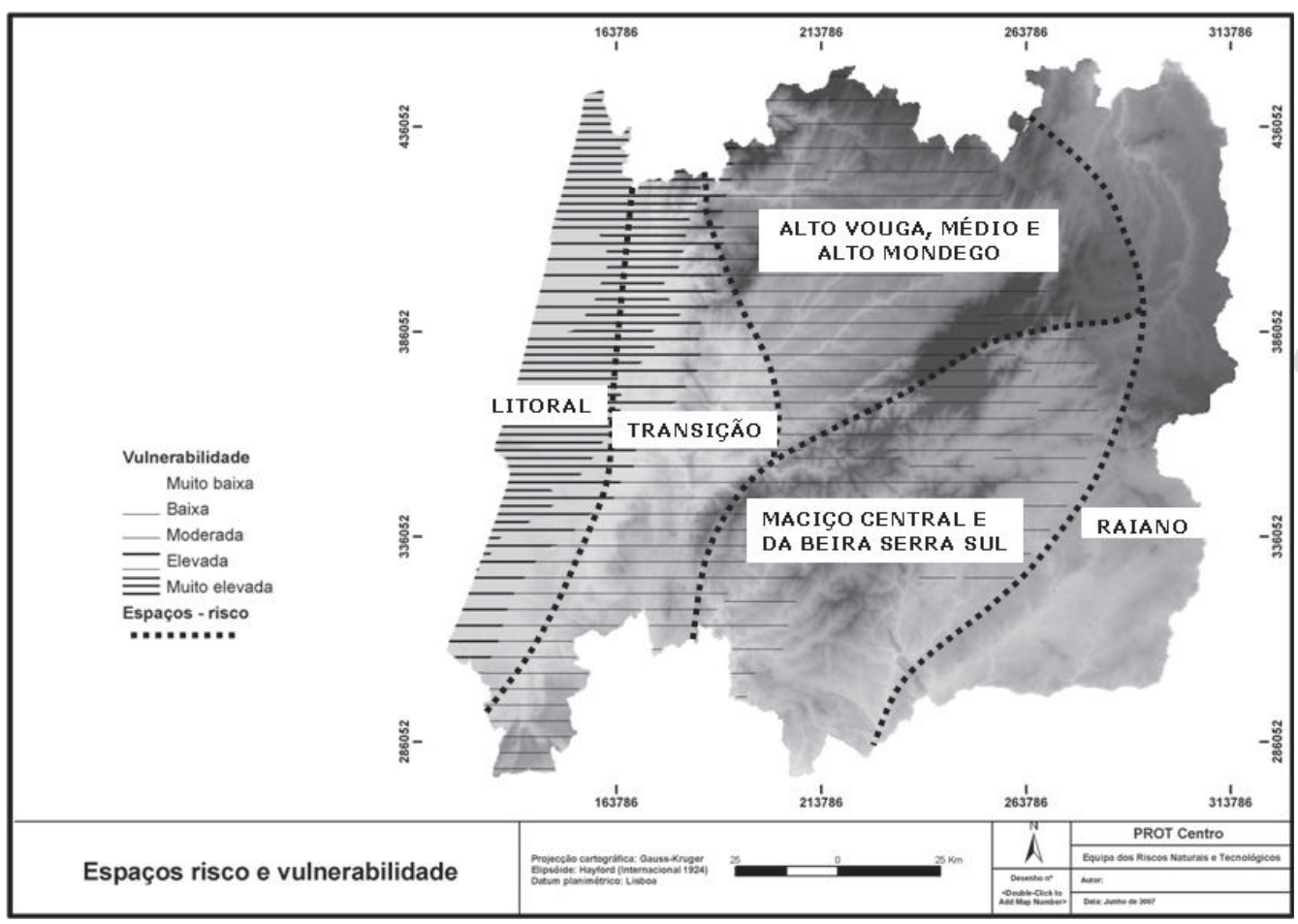

Figura 3 - Espaços-Risco para a Região Centro no âmbito do Modelo Territorial

O desenho de Espaços-Risco permitiu a definição de unidades territoriais capazes de suportar medidas diferenciadas de ordenamento regional e intermunicipal, bem como a adopção de políticas e estratégias específicas no âmbito dos quadros de referência ambiental e de segurança. Pelo significado económico e social de que se revestem as manifestações dos diferentes riscos naturais e tecnológicos, o seu zonamento tem particular incidência, tanto em termos de planeamento estratégico (ordenamento do território e selecção de políticas 
de desenvolvimento), como em termos de planeamento operacional (gestão dos recursos e meios de protecção civil; gestão de recursos hospitalares e de apoio social).

Um diagnóstico, rigoroso e espacializado, dos riscos favorece a escolha de soluções para a redução dos factores de risco, conduzindo à mitigação e contribuindo para a sustentabilidade territorial, conduzindo ainda a que a expressão da vulnerabilidade social aos riscos seja incorporada nas políticas e estratégias de coesão territorial e social.

A valorização dos Espaços-Risco, como tradutores de expressão compósita dos potenciais perigos, promove a adequação e assegura recursos e meios para a protecção e socorro, numa lógica supra-municipal, bem como favorece a infra-estruturação da saúde e apoio social (quantitativamente e qualitativamente), na dependência da tipologia de perigos e dos índices de vulnerabilidade social.

As condições meteorológicas extremas constituem fenómenos determinantes quer (i) nas políticas de saúde pública (ex. ondas de calor nos grupos de risco - crianças, idosos, doentes com patologias específicas - ex. cardíacas), (ii) nas estratégias de melhoria da eficiência energética dos edifícios (aplicação da Directiva 2002/91/CE) associadas a ondas de calor e de frio e de redução da vulnerabilidade social; assim como (iii) em todos os sectores de actividade (indústria, agro-pecuária, serviços, turismo e lazer, desporto, etc.) impondo restrições de circulação e/ou requerendo maior consumo de energia para climatização de edifícios. As políticas de desenvolvimento e infra-estruturação turística devem atender a uma visão sistémica dos riscos naturais e tecnológicos (ex: erosão costeira, contaminação costeira por hidrocarbonetos, incêndios florestais e em áreas protegidas, ondas de calor e de frio, cheias, etc); assim como as políticas de desenvolvimento florestal e rural devem reflectir a prevenção e o risco de incêndio florestal, na componente produtiva, paisagística e ambiental (s.s.).

Ressalta ainda do Modelo Territorial proposto que as estruturas operacionais actualmente existentes, organizadas em torno da organização administrativa dos Distritos (CDOS), configuram uma lógica de actuação territorial supra-municipal o que não se compagina com a projecção espacial dos riscos e da vulnerabilidade social na Região Centro, parecendo adequada uma estruturação da prevenção e mitigação dos riscos, numa escala supra-municipal, em torno das NUT III. Aponta-se assim, para uma estruturação da emergência e do socorro, numa escala supra-municipal, deve ser executada em torno das NUT III, Aponta-se assim, para uma estruturação da emergência e do socorro, numa escala supra-municipal, deve ser executada em torno das NUT III, havendo contudo riscos em que devem estruturados função de meios à escala supra-regional a transnacional.

\section{Orientações e normas estratégicas}

No âmbito do PROT-C foi definido um quadro orientador estratégico, vinculando as entidades públicas, que estabelece um modelo para a organização e estruturação do território. 0 conjunto das geral das propostas de orientação foi organizado, independentemente do grupo de trabalho sectorial, em quatro níveis que compreendiam:

- Princípios gerais de regulação e gestão territorial;

- Normas gerais com aplicação no território de intervenção do PROT-C;

- Orientações específicas com carácter sectorial;

- Normas com aplicação territorial, ao nível das unidades do modelo ou em outras áreas relevantes para as políticas públicas.

Foi assim construída uma matriz de princípios organizadores e normativos suportando o Modelo Territorial proposto no Plano Regional, e definido um conjunto de orientações para os diversos sistemas estruturantes (sistema produtivo, sistema urbano, sistema de acessibilidade e mobilidade, sistema de protecção e valorização ambiental, sistema de gestão dos riscos naturais e tecnológicos). 
Neste contexto o quadro orientador em matéria de políticas de prevenção, redução e mitigação dos riscos no PROT-Centro, estabeleceu um conjunto de princípios gerais e específicos para o uso e transformação do território, orientações estruturantes com incidência intersectorial, assim como referenciais de monitorização e promoção de uma quadro de segurança global para a Região, com expressão nas políticas de ordenamento territorial.

0 quadro orientador pode ser sistematizado em quatro vectores principais de intervenção na Região Centro, que procuram compatibilizar os quadros de referência nacional com as estratégias regionais e locais, no âmbito da gestão dos riscos naturais e tecnológicos e na operacionalização da segurança.

Os quatro vectores estratégicos considerados, com delineação sob a forma de normas gerais, orientações específicas e normas com base territorial foram os que constam na Tabela 2.

\section{Vectores Estratégicos}

Prevenção e redução dos potenciais perigos: visando a promoção de um conjunto de políticas e acções que determinem uma estratégia global de redução do perigo, actuando de

Vector 1 forma antecipada à manifestação dos processos e/ou dinâmicas, e que assegurando a compatibilidade entre o ordenamento do território, uma cultura de segurança e o desenvolvimento físico-urbanístico e socioeconómico.

Redução da vulnerabilidade e mitigação dos riscos: visando o desenvolvimento de acções ou programas específicos para limitar os efeitos decorrentes de acidentes graves ou

Vector 2 catástrofes e avaliar a influência mitigadora instalada, reduzindo a magnitude e a expressão temporal e espacial dos processos e dinâmicas, promovendo o alerta, a redução do grau de exposição dos elementos instalados e incrementando a resiliência das populações.

Operacionalização do socorro e emergência: delineando acções de planeamento e soluções de emergência que conduzam a uma melhor efectivação de medidas de

Vector 3 salvamento, socorro e assistência decorrentes de acidentes graves ou catástrofes, assim como a optimização da gestão de meios de protecção civil e assegurando a coordenação entre as várias políticas sectoriais.

Promoção técnica/cientifica e sensibilização dos cidadãos para a problemática do risco: visando a promoção de acções de investigação e desenvolvimento que assegurem um melhor conhecimento dos processos e dinâmicas relacionadas com a sociedade do

Vector 4 risco, a formação técnica e a difusão de informação para os vários actores, assim como o aumento da resistência social através da consciencialização e responsabilização dos cidadãos sobre práticas e uso do território e da sensibilização para respostas de autoprotecção.

Tabela 2

As orientações e normas por parte da equipa sectorial dos Riscos Naturais, Ambientais e Tecnológicos no âmbito do PROT-Centro incluíram 239 propostas divididas da seguinte forma:

- Princípios Gerais - 48 propostas;

- Orientações específicas sectoriais organizadas do seguinte modo;

- Prevenção e redução da perigosidade - 39 propostas;

- Redução da vulnerabilidade e mitigação dos riscos - 48 propostas;

- Operacionalização do socorro e emergência - 26 propostas;

- Promoção técnica/cientifica e sensibilização dos cidadãos - 22 propostas;

- Orientações de base territorial 56 propostas.

$\mathrm{Na}$ Tabela 3 esquematiza-se a organização conceptual para os riscos naturais e tecnológi$\cos$, a qual foi ulteriormente articulada e organizada em conjunto com os restantes sistemas estruturantes. 
Tabela 3 - Organização das orientações (recomendações e normas), no âmbito dos Riscos Naturais e Tecnológicos

\begin{tabular}{|c|c|c|c|c|}
\hline Tipologia & Princípios & Vectores estratégicos & Âmbito & $\begin{array}{l}\text { Espaços de gestão } \\
\text { territorial do risco }\end{array}$ \\
\hline Orientações & $\begin{array}{l}\text { Gerais }(\mathrm{G}) \\
\text { Domínio Sectorial } \\
\text { (S) } \\
\text { Base territorial (T) }\end{array}$ & $\begin{array}{c}\text { Prevenção e redução } \\
\text { dos potenciais (V1) } \\
\text { Redução da vulnerabilidade } \\
\text { e mitigação dos riscos (V2) } \\
\text { Operacionalização } \\
\text { do socorro e emergência (V3) } \\
\text { Promoção técnico/científica e } \\
\text { sensibilização dos cidadãos para a } \\
\text { problemática do risco (V4) }\end{array}$ & $\begin{array}{l}\text { Nacional (n) } \\
\text { Regional (r) } \\
\text { Intermunicipal } \\
\text { (im) } \\
\text { Municipal (m) }\end{array}$ & $\begin{array}{c}\text { Litoral } \\
\text { Transição Litoral/Interior } \\
\text { Alto Vouga, Médio e Alto } \\
\text { Mondego } \\
\text { Maciço Central e da Beira } \\
\text { Serra sul } \\
\text { Espaço Raiano }\end{array}$ \\
\hline
\end{tabular}

O conjunto alargado de propostas procurou construir um referencial regional em se promovesse uma cultura de segurança e de gestão do risco suportada por políticas sectoriais, de abordagem multidisciplinar, visando o desenvolvimento sustentável.

Estabeleceu-se assim, um quadro de articulação entre os objectivos e instrumentos de ordenamento do território e as políticas de prevenção e redução dos riscos a diferentes escalas de intervenção (nacional, regional, intermunicipal e municipal). 0 desenho das recomendações e normas realçaram um conjunto alargado de acções e instrumentos nos quais se devem alicerçar as políticas públicas, como as que estabelecem a cartografia, monitorização, cadastro e tratamento de dados, bem como as relevantes para a análise dos perigos, definição da probabilidade de ocorrência e expressão territorial do risco, assim como para a gestão da emergência e socorro.

Para um conjunto alargado de processos naturais propõe-se a incorporação nos Planos Municipais de Ordenamento do Território de condicionantes na ocupação e uso do território ou a adopção de espaços vocacionados para determinados usos e actividades. Foi igualmente defendida a implementação de programas específicos de análise, concepção, modelação e mitigação do perigo em áreas susceptíveis, ou por conterem infra-estruturas ou equipamentos específicos e críticos, e para os quais a análise custo-benefício, ou a adopção de métodos perequativos que poderão constituir mecanismos de intervenção territorial na gestão do risco.

A aplicação do conjunto de orientações à escala regional permite a construção e a robustez de ferramentas e parâmetros de actuação na prevenção e mitigação dos riscos, constituindose o ordenamento do território como uma forma estrutural de segurança das populações ao permitir a redução estrutural da vulnerabilidade social numa lógica de desconcentração urbana e de diversificação dos investimentos produtivos, e ao promover a recuperação do edificado e a melhoria da qualidade de vida nos hinterlands dos grandes centros urbanos, nomeadamente com a construção de equipamentos sociais e de qualificação ambiental.

As orientações propostas estabelecem um conjunto de pressupostos que visam estimular a participação dos cidadãos e das suas estruturas associativas, de âmbito local, em tarefas ligadas à segurança e à protecção civil, possibilitando a construção de epistemologias cívicas em torno dos perigos naturais e tecnológicos e da vulnerabilidade social, num quadro de informação e participação pública. 


\section{Conclusões e expectativas}

A visão e diagnóstico produzidos pela equipa do sistema estruturante dos Riscos Naturais e Tecnológicos no âmbito do PROT - Centro estabeleceu um novo referencial territorializado para a prevenção, redução e mitigação do risco.

A expressão cartográfica da susceptibilidade associada a processos ou acções com impactos negativos na Região, a par da análise da vulnerabilidade social municipal, permite adoptar estratégias e acções inovadoras no âmbito do planeamento estratégico, bem como no planeamento operacional.

A espacialização encontrada para a expressão dos factores de risco, assim como a construção de Espaços-Risco favorece a escolha de soluções para a redução dos factores de risco, conduzindo à mitigação e contribuindo para a sustentabilidade territorial. Esta mesma resolução cartográfica permite a integração multi-escalar das políticas de gestão do risco e favorece a articulação entre os instrumentos de ordenamento municipal com os recursos infraestruturais e operacionais de protecção civil.

0 quadro intersectorial estabelecido na construção do Modelo Territorial para a Região Centro permite, em conjunto com os demais sistemas estruturantes, estabelecer programas e directrizes de uso e transformação do território, bem como desenhar opções estratégicas de base territorial e um quadro normativo e orientador, visando o reforço da coesão e dos fluxos territoriais.

O Modelo construído fez salientar que a prevenção, redução e a mitigação dos riscos determinam a qualificação das instituições e organizações, a nível municipal e supra-municipal, e a dotação de recursos humanos, assim como condicionam a especialização técnica e científica, com capacidade de criar conhecimento e informação pública, ou com capacidade de actuação em caso de acidentes ou catástrofes.

As propostas orientadoras e normativas fazem salientar a articulação entre os vários níveis da administração, a partir de um referencial regional, multi-escalar, em se promove uma cultura de segurança e de gestão do risco suportada por políticas públicas sectoriais.

0 estabelecimento de políticas de ordenamento assentes na expressão territorial dos riscos naturais e tecnológicos promove epistemologias cívicas, através da participação dos cidadãos e das suas estruturas associativas, e o reconhecimento das instituições e das vivências.

A participação da equipa do sistema estruturante dos Riscos Naturais e Tecnológicos no âmbito do PROT - Centro, atendendo ao carácter pluridisciplinar de partida, à assumpção de interacções sectoriais, à visão e o Modelo delineado, às propostas multi-escalares para os instrumentos e políticas, procurou contribuir para a qualificação e eficiência da gestão territorial regional e para a definição de novas estratégias de desenvolvimento.

Alexandre Oliveira Tavares

(Coordenador do Sistema Estruturante - Riscos Naturais e Tecnológicos no PROT-Centro) Faculdade de Ciências e Tecnologia, Centro de Estudos Sociais, Universidade de Coimbra. 